\title{
Justiça Ecológica e Subalternização Feminina
}

Ecological Justice and Female Subalternization

\section{Camila Damasceno de Andrade ${ }^{1}$}

${ }^{1}$ Universidade Federal de Santa Catarina, Florianópolis Santa Catarina, Brasil. E-mail: camila_damasceno17@hotmail.com. ORCID: https://orcid.org/0000-0002-5907-3541.

Artigo recebido em 17/01/2019 e aceito em 1\%/08/2019.

\section{$(\mathrm{cc}) \mathrm{BY}$}

This work is licensed under a Creative Commons Attribution 4.0 International License. 


\section{Resumo}

Este artigo tem o objetivo de verificar como a crise ambiental afeta as mulheres subalternizadas no Brasil, elencando os fatores que conduziram à precarização de sua qualidade de vida e ao processo de feminização da pobreza. Nesse sentido, fazendo uso do método indutivo, inicialmente, revisitam-se alguns dos principais elementos trabalhados pelas matrizes teóricas da justiça ecológica e da ecologia política, demonstrando que os riscos e impactos ambientais são partilhados de maneira desigual entre os diversos grupos sociais, o que atinge as mulheres desproporcionalmente. Em um segundo momento, apresenta-se o conceito de organização social de gênero como essencial para a compreensão da posição subalternizada ocupada pelas mulheres nas sociedades outrora colonizadas, o que é feito a partir do aporte teórico dos feminismos decoloniais. Posteriormente, demonstra-se como o processo de feminização da pobreza expõe grande parte das mulheres aos riscos e impactos ambientais, enfatizando a perspectiva pragmática da justiça ecológica como um possível caminho para a promoção da equidade de gênero.

Palavras-chave: Colonialidade; Crise ambiental; Feminização da pobreza; Gênero; mulheres.

\section{Abstract}

This article aims to verify how the environmental crisis affects subaltern women in Brazil, listing factors that led to the precariousness of their quality of life and to the process of feminization of poverty. In this way, using the inductive method, initially it reviews some of the main elements treated by the theoretical frameworks of the ecological justice and ecological politics, showing that the environmental risks and impacts are shared unequally among the various social groups, which hits women disproportionately. At a second moment, it presents the concept of gender social organization as essential for the understanding of the subaltern position occupied by women in societies once colonized, which is done from the theoretical contribution of the decolonial feminisms. Afterwards, it demonstrates how the process of feminization of poverty exposes most women to environmental risks and impacts, emphasizing the pragmatic perspective of ecological justice as a possible path for the promotion of gender equality.

Keywords: Coloniality; Environmental crisis; Feminization of poverty; Gender; Women. 
Introdução

A chamada crise ambiental tem se incrementado a cada ano, na medida que novas formas de degradação do meio ambiente surgem e se difundem a nível global. Se o processo de globalização já foi iniciado há séculos, desde o surgimento do colonialismo mundial advindo das expedições europeias ultramarinas, observa-se, hoje, que esse processo vem sendo cada vez mais intensificado, com impactos diretos e irreversíveis ao meio ambiente através de uma exploração desmedida de recursos naturais. Concomitantemente, verifica-se, também, o surgimento de uma série de conflitos socioambientais que afetam agrupamentos humanos de forma desigual em função de diferenciações étnicas, raciais, de classe e de gênero.

A crise ambiental, por conseguinte, não se configura meramente como uma questão ecológica, porquanto impacta diretamente a vida social, além de ter sido ocasionada pelos próprios seres humanos ao meio ambiente e ao seu entorno (MELO, 2016, p. 35-37). A esse respeito, esclarece Melo (2016, p. 37): "a problemática contemporânea não tem raízes ecológicas, suas causas estão situadas na intervenção humana sobre os sistemas e ciclos ecológicos, portanto, tem uma origem social". Isso significa que a natureza, antes encarada como um fenômeno externo à sociedade, passa a ser vista como fenômeno interno, fabricado por essa mesma sociedade, e não mais predeterminado. Em outras palavras, pode-se afirmar que a natureza foi absorvida pelo sistema industrial (BECK, 2011, p. 9).

Se, por um lado, a noção de progresso foi o elemento que impulsionou as mudanças que caracterizaram o processo de industrialização iniciado no século XVIII, por outro, o período pós-industrial vivenciado na contemporaneidade tem a noção de crise como o elemento central que caracteriza as reflexões teóricas e as práticas sociais hodiernas. Houve, pois, uma deturpação do ideal de progresso concebido pela modernidade, dado que as mudanças não são mais necessariamente tomadas a partir de uma visão otimista (MELO, 2016, 37). Pelo contrário, hoje as mudanças são sinônimo de riscos, que expressam uma crise ambiental global derivada da degradação ecológica praticada a nível planetário (BECK, 2011). 
Nesse sentido, conforme $\operatorname{Beck}^{1}$ (2011, p. 9-10), contra as ameaças da natureza externa, a exemplo das guerras, é possível se proteger erguendo barreiras, mas contra as ameaças da natureza interna, agora modificada pela exploração humana e absorvida pelo sistema industrial, somente aqueles que detêm os meios de produção são capazes de se defender. Mesmo eles, no entanto, podem estar indefesos em situações extremas e imprevisíveis, dado que os riscos ambientais são transfronteiriços e, em certa medida, universais.

Para Beck, portanto, a lógica da distribuição dos riscos obedece ao chamado "efeito bumerangue", segundo o qual os responsáveis pela produção e reprodução dos riscos civilizacionais serão, também, alcançados e expostos a eles. Segundo essa noção, os próprios centros causais de produção dos riscos são afetados, assumindo, ao mesmo tempo, a posição de vítimas e culpados. A bomba atômica, que elimina até mesmo o agressor, exemplificaria essa situação (BECK, 2011, p. 44-45).

No entanto, ao contrário do que foi preceituado por Beck, ainda não é possível se falar em uma democratização dos riscos. Muito embora o aquecimento global, a escassez de água, a concentração de gases poluentes na atmosfera, a crise alimentar e tantos outros fenômenos decorrentes do desenvolvimento industrial tenham efeitos universais, podendo afetar não apenas uma dada sociedade, mas o planeta como um todo, é ingênuo acreditar que esses males romperam com as diferenças socioeconômicas entre os Estados e, dentro deles, entre os diversos estratos sociais, como se todos estivessem igualmente sujeitos a sua ação catastrófica.

Afinal, numa sociedade marcada por desigualdades estruturais, complexas e profundas, não se pode apenas tangenciar a dimensão social da crise ambiental. Num cenário em que algumas sociedades e grupos específicos terão de suportar com maior intensidade os efeitos desses riscos, em decorrência de suas debilidades econômicas

\footnotetext{
${ }^{1} \mathrm{~A}$ menção às obras de Beck é feita aqui com o intuito de elucidar o conceito de risco ambiental. Salientase, contudo, que o referido autor diverge da corrente teórica da justiça ecológica, que constitui o referencial adotado nesta pesquisa. Enquanto Beck sustenta a democratização dos riscos ambientais, afirmando que se vive, hoje, numa modernidade reflexiva na qual a sociedade seria caracterizada pela presença ostensiva dos riscos, a justiça ecológica contraria esta premissa, entendendo que os riscos são distribuídos de maneira desigual. Ademais, Beck ignora a persistência das estratificações sociais: para o autor, enquanto, na sociedade industrial, a lógica de produção de riqueza domina a lógica de produção de riscos, na chamada sociedade de risco esta relação se inverte. A justiça ecológica, por sua vez, pressupõe a manutenção do sistema de exploração capitalista e das demais estruturas que sustentam as desigualdades sociais, entendendo que categorias como raça, gênero e classe são fundamentais no contexto da criação e da distribuição dos riscos. Em outras palavras, a justiça ecológica não aceita a ideia de que a sociedade industrial foi superada por um novo sistema de organização social.
} 
frente aos países centrais e aos estratos mais favorecidos, não há que se falar em democratização de riscos, mas em riscos desigual e injustamente partilhados.

Com base nesses pressupostos, pretende-se discutir como essa distribuição desigual dos riscos ambientais afeta as mulheres subalternizadas no Brasil, que se encontram entre os agrupamentos sociais mais vulneráveis aos impactos derivados da crise ambiental e civilizacional ainda em expansão. Fazendo uso do método indutivo, adotam-se os referenciais teóricos da justiça ecológica e da ecologia política para abordar a problemática da desigualdade na distribuição dos riscos e, no que se refere à posição subalternizada ocupada pelas mulheres, utiliza-se a matriz teórica dos feminismos decoloniais.

Num primeiro momento, revisita-se, sem qualquer pretensão de exaurir o tema, o percurso histórico dos movimentos de justiça ambiental, hoje abrangidos pela vertente mais ampla da justiça ecológica. A partir da compreensão de que as mulheres são - intencionalmente ou não - as principais destinatárias dos riscos e danos ambientais, discute-se o conceito de organização social de gênero como estruturante das hierarquias de gênero da modernidade. Em seguida, aborda-se a temática do processo de feminização da pobreza, que ilustra a posição desfavorecida das mulheres dentro do sistema capitalista global e mais especificamente no Brasil. Enfim, retoma-se a perspectiva pragmática da justiça ecológica como uma possibilidade de enfrentamento

à dominação masculina e, consequentemente, como uma forma de promoção da equidade de gênero.

\section{1 (In)Justiça Ecológica e Distribuição de Riscos}

Os movimentos e teorias de caráter socioambiental, em princípio, surgiram com o intuito de criticar a ausência de isonomia no acesso aos bens da natureza e a distribuição desigual dos riscos ambientais, valendo-se da percepção de que esses riscos e impactos atingem determinados grupos sociais de maneira muito mais intensa do que outros (LEITE et al, 2017, p. 183). Essa distribuição desigualitária acompanha, por sua vez, outras desigualdades sociais que já inseriam esses agrupamentos humanos em condições de maior vulnerabilidade e exclusão social, que, por sua vez, foram agravadas pela incidência dos riscos ambientais. 
Se a baixa renda, por exemplo, conduz certas pessoas e comunidades para regiões periféricas e subalternizadas, é preciso ter em conta que essas regiões são quase sempre representativas de riscos para a saúde e segurança de seus habitantes. Encostas de morros sujeitos a deslizamentos, áreas industriais tornadas insalubres pela poluição do ar, bairros sem acesso ao saneamento básico, entre outros fatores, expõem uma série de populações a doenças e a lesões a sua integridade física, ou, conforme Capdeville (2017, p. 489), forçam-nas a se deslocarem em busca de melhores condições de habitação. Percebe-se, ainda, que não é uma coincidência que grande parte das pessoas expostas a esses riscos sejam, além de pobres, também negras.

Destarte, o movimento de justiça ambiental surge nos Estados Unidos em meados da década de 1980 como uma crítica profunda a essa distribuição desigual dos riscos ambientais, buscando uma reconfiguração da cidadania para que a ela seja atribuída uma característica global (LEITE et al., 2017, p. 183). Para tanto, o movimento passou a enfatizar que populações já vulnerabilizadas por sua raça e classe eram também as principais vítimas da devastação ambiental. Recebeu, entre outras nomenclaturas, a alcunha de movimento contrário ao racismo ambiental ${ }^{2}$, dado que se originou da luta de populações negras norte-americanas que se insurgiram contra o depósito de lixo tóxico nas áreas por elas habitadas (ACSELRAD et al., 2009, p. 17).

Assim, os movimentos por justiça ambiental congregaram duas importantes percepções: a crise ambiental centraliza os benefícios do desenvolvimento na mesma medida que destina os seus malefícios aos grupos populacionais despossuídos e, por outro lado, essas pautas não são incluídas nas agendas governamentais e das grandes corporações (ACSELRAD et al., 2009, p. 15).

Ademais, as reivindicações por justiça ambiental não se detêm somente na busca por uma melhor distribuição dos riscos ambientais, indo além de uma concepção de justiça meramente distributiva. Schlosberg (2007) destaca a proeminência dos debates acerca da justiça distributiva no âmbito ecológico, ressaltando a necessidade de se ampliar essa discussão para que teorias sobre sustentabilidade ambiental também possam abranger as noções de justiça como reconhecimento e como participação ${ }^{3}$.

\footnotetext{
2 De acordo com Rammê (2012, p. 18), "o racismo ambiental exprime o fenômeno pelo qual muitas das políticas públicas ambientais, práticas ou diretivas acabam afetando e prejudicando de modo desigual, intencionalmente ou não, indivíduos e comunidades de cor".

${ }^{3}$ Não se ignora que a justiça ultrapassa a lógica distributiva, englobando também o aspecto participativo e do reconhecimento. No entanto, os limites desta pesquisa impedem um maior aprofundamento dessas
} 
A ausência de reconhecimento nos domínios social e político traz danos aos indivíduos e comunidades oprimidos, e pode ser percebida através da desvalorização desses agrupamentos sociais. Nesse sentido, a falta de reconhecimento está na base da injustiça distributiva (SCHLOSBERG, 2007, p. 14). Outrossim, a justiça participativa também se interconecta às abordagens do reconhecimento e da distribuição, evocando a necessidade de maior igualdade nos procedimentos democráticos de tomada de decisões. Em outras palavras, para se enfrentar adequadamente as injustiças, seja no âmbito distributivo, seja no âmbito do reconhecimento, é necessária a garantia da democracia participativa.

Segundo Baggio (2008, p. 13), "na justiça ambiental, o que se quer, a priori, é a superação das desigualdades (im)postas pelo próprio processo de produção capitalista". Tendo como finalidade a garantia da igualdade material, a necessidade de se instituir mecanismos distributivos dos riscos de caráter isonômico deve ser aliada às lutas pela "democratização da participação nos processos decisórios institucionais" (BAGGIO, 2008, p. 14) e também à valorização dos indivíduos e grupos sociais marginalizados.

Acselrad (et al., 2009, p. 40-41) designa justiça ambiental como um conjunto de princípios e práticas que:

\begin{abstract}
-asseguram que nenhum grupo social, seja ele étnico, racial ou de classe, suporte uma parcela desproporcional das consequências ambientais negativas de operações econômicas, decisões de políticas e programas federais, estaduais, locais, assim como da ausência ou omissão de tais políticas;

-asseguram amplo acesso às informações relevantes sobre o uso dos recursos ambientais, a destinação de rejeitos e a localização de fontes de riscos ambientais, bem como processos democráticos e participativos na definição de políticas, planos, programas e projetos que lhe dizem respeito; -favorecem a constituição de sujeitos coletivos de direitos, movimentos sociais e organizações populares para serem protagonistas na construção de modelos alternativos de desenvolvimento que assegurem a democratização do acesso aos recursos ambientais e a sustentabilidade do seu uso.
\end{abstract}

Trata-se de um movimento que tem como principal bandeira a concretização da justiça social, mais especificamente dentro da temática ambiental. Apesar de ter surgido nas ruas como resultado de lutas sociais, foi incorporado pela academia e hoje está refletido nas teorias acerca da justiça ambiental e da ecologia política, que já ultrapassam, hoje, o alcance de suas abordagens iniciais.

abordagens, dando-se ênfase à distribuição desigual dos riscos ambientais. Para um maior desenvolvimento do tema, sugere-se a leitura de Schlosberg (2007) e Baggio (2008). 
A justiça ecológica surge como uma dessas vertentes que vai se debruçar sobre os mais diversos conflitos socioambientais, além de incorporar a proteção da natureza e dos animais não humanos à crítica acerca da distribuição desigual dos riscos (LEITE et al., 2017, p. 183-184). Ela aprofunda o debate já iniciado pela justiça ambiental, estendendo a luta por justiça social para grupos não abrangidos pelo discurso protetivo anterior, como as mulheres, indo além da lógica antropocêntrica que valoriza o humano em detrimento da natureza. Além disso, ela se diferencia da abordagem realizada pela justiça ambiental ao buscar instituir mecanismos capazes de modificar as formas de atuação humana que têm conduzido à degradação da natureza (BAGGIO, 2008, p. 13).

A justiça ecológica sintetiza um conjunto de reivindicações de movimentos socioambientais e de teóricos críticos da distribuição desigual dos riscos, buscando tutelar as regiões e os grupos sociais desfavorecidos e marginalizados pelo processo de globalização capitalista, além de também voltar o seu interesse para as demandas estritamente ecológicas, como é o caso da luta pela positivação de direitos aos animais não humanos e à própria natureza. ${ }^{4}$

A justiça ecológica, portanto, revela-se como um advento do socioambientalismo, concretizando-se como um ponto de intersecção entre as demandas de cunho social e ambiental, buscando uma maior valorização das reivindicações dos grupos populacionais que são marginalizados no contexto da exploração da natureza. Verifica-se, por conseguinte, que a promoção da participação

\footnotetext{
${ }^{4}$ David R. Boyd (2017) discute a possibilidade de se conferir direitos para a própria natureza em sua obra homônima, "The rights of nature". Observa-se que o objetivo não é discutir a questão de se conferir direitos aos humanos relativos ao meio ambiente. A proposta se vincula a uma lógica biocêntrica, não entendendo apenas que os humanos devem ter direitos que Ihes garantam um meio ambiente saudável e equilibrado, por exemplo, mas que o próprio meio ambiente e seus recursos naturais - rios, árvores, montanhas etc. devem ter a possibilidade de serem titulares de direitos positivados. Nesse sentido, Boyd aponta uma série de precedentes judiciais e legislativos em que o meio ambiente figurou como parte em processos, pleiteando direitos, além de trazer exemplos de comunidades locais que conseguiram editar leis municipais que positivavam direitos para a natureza. A título de exemplo, cita-se o caso Disney vs. Sierra Club, em que a empresa visava construir uma estação de esqui e resort no Mineral King Valley, região remota bastante apreciada pelos seus recursos naturais e por ser habitat de diversos animais. A associação ambientalista Sierra Club apresentou uma ação judicial em nome do vale prejudicado pela construção do empreendimento, levando para os tribunais norte-americanos, pela primeira vez, a discussão acerca da legitimidade processual da natureza. Anos mais tarde, a problemática em torno do fraturamento hidráulico deu origem à primeira legislação comunitária que reconheceu os direitos da natureza. $\mathrm{O}$ caso aconteceu em Tamaqua Borought, uma pequena cidade da Pensilvânia, na qual foi editada uma portaria para evitar que o lodo do esgoto fosse despejado em poços de mineração, o que poderia contaminar a água potável. A portaria reconhece direitos legais às comunidades naturais e aos ecossistemas, além de permitir que qualquer pessoa possa agir juridicamente em nome da natureza para defendê-la de danos causados pelo despejo do esgoto. Essa inovação legislativa abriu portas para que outras leis municipais fossem editadas em prol da natureza em diversas outras comunidades dos EUA, como Pittsburgh na Pensilvânia; Santa Monica na Califórnia; Condado de Mora no Novo México; Atenas em Ohio; Mountain Lake Park em Maryland; e Broadview Heights em Ohio.
} 
social ativa na gestão ambiental configura uma pauta de extrema relevância para os ativistas e teóricos da justiça ecológica, considerando que a distribuição desigual dos riscos civilizacionais se deve, entre outros fatores, à exclusão desses grupos vulneráveis do processo democrático.

A justiça ecológica amplifica os obstáculos encontrados pela justiça ambiental, que já era criticada por conciliar as questões ambiental e social. Ao incluir nos debates por justiça a própria natureza como um possível destinatário ou sujeito de justiça, as preocupações ecológicas se ocupam da proteção do humano sem deixar de lado a proteção dos animais e do meio ambiente (SCHLOSBERG, 2007, p. 106). Reconhecem a centralidade da ação humana para a crise que se vivencia, mas sem esquecer que é sobretudo o sistema de exploração capitalista o responsável pelo cenário atual.

Nesse diapasão, entende-se que a justiça ecológica dialoga diretamente com a perspectiva da ecologia política, diferenciando-se desta apenas no que diz respeito ao campo de ação, dado que a justiça ecológica se vincula a um viés mais pragmático, enquanto a ecologia política se restringe ao âmbito teórico, buscando articulações mais estritas com a ecologia biofísica. Ambas, no entanto, atuam na intersecção da ecologia com as ciências sociais, e se debruçam sobre os conflitos socioambientais a partir da perspectiva das populações vulneráveis, atuando contra a distribuição desigual dos riscos e dos impactos gerados pela crise ambiental, denunciando o caráter racista, classista e patriarcal que estrutura essa desigualdade.

Conforme Leff (2006):

A ecologia política se estabelece no campo do conflito pela reapropriação da natureza e da cultura, ali onde a natureza e a cultura resistem à homologação de valores e processos (simbólicos, ecológicos, políticos) incomparáveis e a serem absorvidos em termos de valor de mercado. É ali que a diversidade cultural adquire direito de cidadania como uma política da diferença, de uma diferença radical, mais além da distribuição equitativa do acesso e dos benefícios econômicos derivados da atribuição de um valor à natureza.

Assim, tanto a justiça ecológica como a ecologia política vão ressaltar que se vive, na verdade, uma era de injustiça ecológica, em que a crise ambiental reproduz as desigualdades que sustentam a sociedade capitalista moderna. Nesse sentido, a distribuição desigual dos riscos ambientais tem correspondência direta com a segregação socioespacial que toma conta, em especial, das zonas urbanas, conquanto também se verifique nas zonas rurais. $\mathrm{O}$ inchaço das grandes metrópoles, provocado por 
séries de deslocamentos populacionais, contrapõe edifícios modernos e luxuosos às favelas e periferias, privadas das condições básicas de urbanidade e marcadas por precariedade e miséria. Nesse aspecto, o processo de construção da sociedade pósindustrial, mesmo quando prevê articulações entre os espaços, empenha-se em varrer os indesejados para longe das áreas centrais, condenando-os à vida em regiões de risco habitacional.

A esse respeito, ressalta-se que as configurações urbanas vêm se desenvolvendo de maneira cada vez mais peculiar e diferenciada das formações urbanísticas convencionais, nas quais há um centro urbano desenvolvido, rodeado por uma periferia pobre e segregada. Em diversas cidades, a segregação socioespacial se construiu a partir da formação de bolsões de pobreza no interior da área central, muitas vezes escondidos em razão da própria configuração geográfica do local (SUGAI, 2015). Não se pode, portanto, reduzir a problemática a uma questão localizacional.

Com base nesses pressupostos, nota-se que, entre esses grupos desproporcionalmente expostos aos riscos ambientais e com menores habilidades para a prevenção de danos (CAPDEVILLE, 2017, p. 489), as mulheres figuram como uma das partes mais vulneráveis da crise que se alastrou com a difusão do modelo civilizacional capitalista (crise esta que pode ser percebida através da destruição de ecossistemas, da expansão do agronegócio, da perda de biodiversidade, das mudanças climáticas em nível global, do incremento da poluição das águas e do ar, entre diversos outros fatores). A segregação socioespacial impulsionada pelo capitalismo confinou boa parte das mulheres subalternizadas em regiões periféricas expostas a ameaças a sua saúde e segurança. Numa era de globalização perversa (SANTOS, 2001), a pobreza adquire a particularidade de ser estrutural e generalizada, sendo necessário escondê-la longe das regiões mais valorizadas.

Nessa senda, Segato (2013, p. 72) observa que as formas de crueldade e violência contra as mulheres aumentaram e se modificaram à medida que a modernidade e o mercado se expandiram e anexaram novas regiões. Percebe-se, portanto, que os corpos femininos vêm sendo depredados e violentados das mais diferentes formas desde o colonialismo, que encontra, hoje, na devastação ambiental a mais nova forma de subjugar as mulheres. Essa premissa é sustentada pela perspectiva feminista da justiça ecológica, que defende que as mulheres configuram o grupo social mais afetado pelos riscos e impactos socioambientais que afligem as populações 
desfavorecidas, vendo-se violadas não apenas pelo Estado e pelas grandes empresas que interferem diretamente em suas vidas, mas também por uma estrutura patriarcal que as oprime e invisibiliza a sua participação no trabalho produtivo. Em outras palavras, a distribuição desigual dos riscos socioambientais afeta as mulheres subalternizadas com maior vigor.

\section{A Organização Social de Gênero}

Restrepo e Rojas (2010) vão se referir aos estudos e argumentos acerca da decolonialidade como "inflexão decolonial", que pretende expressar um nível mais amplo de subversão que vai além da libertação político-administrativa, mas engloba a emancipação das relações de poder imbricadas na cultura, nos saberes, nas mentalidades e nas diversas esferas de organização social.

O conceito de colonialidade do poder exprime a constatação de que os processos de independência e o consequente surgimento de Estados-nação supostamente livres não foram o suficiente para acabar com a lógica colonial nas esferas econômica e política. Por outras palavras, o colonialismo, no sentido histórico, pode até ter cessado, mas a colonialidade permanece (BALLESTRIN, 2013, p. 99-100). O fim das administrações coloniais não acabou com as formas coloniais de dominação, cuja continuidade pode ser percebida através da hierarquização étnico-racial, da divisão internacional do trabalho, da oposição entre centro e periferia, entre Sul e Norte, entre Ocidente e Oriente.

É a partir dessa premissa que Quijano (2005, p. 227) defende que a constituição da América e a expansão do capitalismo culminaram no processo de globalização em curso, que redefiniu os padrões de poder a partir da racialização da população mundial. As hierarquizações sociais passam a tomar a ideia de raça como eixo fundamental, expressando-se por meio da experiência da dominação colonial e do eurocentrismo como modelo de racionalidade. Nota-se, por sua vez, que o caráter colonial desse processo ultrapassa a matriz histórica do colonialismo, perpetuando-se através da colonialidade enquanto elemento imbricado no padrão de poder hegemônico.

Há, entretanto, outro instrumento de dominação social universal, mais antigo, inclusive, do que os elementos raça e classe. Trata-se da organização social de gênero, 
que toma as diferenças biológicas entre homens e mulheres como critério para hierarquizá-los socialmente. Ainda que a desigualdade de gênero já existisse antes da colonização, ela é potencializada a partir dela, uma vez que o patriarcado pré-colonial obedecia à outra estrutura, transformando-se em uma forma muito mais letal para as mulheres a partir da imposição do padrão colonial (SEGATO, 2013, p. 80-82).

Ademais, a imbricação entre as categorias raça e gênero passa a atingir as mulheres de maneira violenta com a ascensão da colonialidade. Conforme Spivak (2010, p. 67), "se, no contexto da produção colonial, o sujeito subalterno não tem história e não pode falar, o sujeito subalterno feminino está ainda mais profundamente na obscuridade". Destarte, a colonialidade não se refere somente à classificação racial, mas é um fenômeno que abarca, também, o controle do sexo e das demais esferas da existência social.

Entendendo o gênero como um sistema de organização social que toma o sexo como ponto de partida para a atribuição de papéis e estereótipos às mulheres e aos homens, as diversas críticas feministas vão denunciar a construção cultural de modelos idealizados do feminino e do masculino. Demonstraram, assim, que a discriminação em função do sexo não tem raiz em características biológicas, mas em causas sociais (MENDES, 2014, p. 86), e que o gênero não é somente o elemento constitutivo das relações sociais que se baseiam nas diferenciações entre os sexos, mas é uma estrutura primária que significa as relações de poder (SCOTT, 2008, p. 64).

A dominação masculina se projeta em todo um conjunto de instituições que mantêm e reforçam os papéis e estereótipos de gênero. O feminismo veio desnudar o caráter histórico do patriarcado, demonstrando que a inferiorização feminina não passa de construção social que foi naturalizada, fundamentando-se no domínio do homem sobre a mulher, promovido por meio de todas as instâncias sociais (MENDES, 2014, p. 86-87).

Nos trilhos da crítica ao eurocentrismo, os estudos feministas decoloniais contestaram as pretensões universalizantes tanto das teorias críticas masculinizadas que se referem ao homem como representativo da espécie humana, quanto dos feminismos liberais, que, apesar de reconhecerem a mulher como sujeito, referem-se a uma mulher "universal" - branca e de boa posição econômica - como representativa das demais. Ao entenderem que o conhecimento e o conhecedor devem ser situados, as teóricas 
feministas decoloniais passaram a desempenhar o importante papel de questionadoras do pensamento eurocêntrico e de seus dogmas.

Assim, no contexto do padrão de poder capitalista global, é preciso situar o gênero enquanto categoria colonial para compreender o papel por ele desempenhado na reprodução de seus padrões de opressão. Nesse sentido, o conceito de colonialidade de gênero se torna essencial para se discutir a dominação masculina em países outrora colonizados, como é o caso brasileiro, pois parte do pressuposto de que, ao lado do capitalismo e do racismo, o gênero se configurou como um dos principais instrumentos de classificação e dominação social desde o colonialismo.

Os debates feministas decoloniais reconhecem o gênero como categoria central para a estruturação do colonialismo e da colonialidade, considerando que o próprio capitalismo global se valeu das assimetrias de gênero na construção de seus alicerces contemporâneos - como se percebe com a divisão sexual do trabalho, que atribui às mulheres o trabalho reprodutivo. Nessa senda, o gênero constitui elemento estruturador da colonialidade do poder, e não uma categoria acessória já superada. Conforme Segato $(2013$, p. 80 ), apesar de sua tipificação como tema particular pelo discurso sociológico e antropológico, as relações de gênero são "uma cena ubíqua e onipresente de toda vida social".

Vale-se, aqui, da premissa segundo a qual o processo colonizador exacerbou as hierarquias de gênero, tornando-as perversas e autoritárias, o que se percebe a partir de uma correlação entre a dominação masculina sobre as mulheres e a dominação também masculina, em regra - dos humanos sobre a natureza.

As críticas feministas e, em especial, a crítica realizada pelas correntes ecofeministas, debruçam-se sobre a correspondência entre dominação masculina e dominação da natureza. O feminismo, enquanto movimento social, busca a igualdade entre homens e mulheres e, no campo teórico, procura explicar a posição desfavorecida que as mulheres ocupam em comparação com os homens, buscando as suas origens e as suas consequências. Entretanto, para além de um movimento de luta social e de um campo teórico, o feminismo também é dotado de um sentido político, que atua em prol da igualdade de direitos. Essas três acepções do feminismo dialogam entre si, sendo que é o campo teórico que possibilita a tomada de posturas políticas que, por sua vez, vão impulsionar os movimentos sociais (SILVA, 2017, p. 569-570). 
Ao longo do desenvolvimento das críticas feministas, elas acabaram se aproximando de outros debates teóricos realizados nas ciências sociais acerca das desigualdades, o que permitiu a aproximação entre o feminismo e o ambientalismo. Põem-se em evidência, a partir de então, a interconexão entre dominação masculina e dominação da natureza, entendendo que mulheres e meio ambiente estão sujeitos a estruturas opressoras correspondentes.

As mulheres e a natureza são, ambas, assimiladas pelo capitalismo como uma "coisa útil", como um objeto de consumo, passando por um processo de reificação em que se veem submetidas a uma exploração cotidiana. O homem branco e capitalista, portanto, projeta uma dupla dominação que afeta as mulheres subalternizadas e o próprio mundo natural (SILVA, 2017, p. 571).

Nesse sentido, convém retomar a discussão acerca da distribuição desigual dos riscos ambientais e a desproporcionalidade com a qual esses riscos atingem as mulheres, uma vez que a crise civilizacional que se vivencia hoje é produto dessa colonialidade que potencializa a hierarquização de gênero.

\section{Processo de Feminização da Pobreza}

Conforme apontam os indicadores sociais, a imensa maioria das famílias brasileiras com renda inferior à linha de pobreza e de indigência é chefiada por mulheres, demonstrando que, ao menos no Brasil, "a pobreza é essencialmente feminina" (MATOS, 2005, p. 13). A percepção de que há um predomínio crescente de mulheres entre a população empobrecida é o que se convencionou chamar de "feminização da pobreza", processo que vem sendo diagnosticado desde a década de 1970 e que tem dado visibilidade para a necessidade de políticas públicas que incorporem à categoria gênero aos seus debates (AGUILAR, 2011, p. 127).

O termo não significa, necessariamente, que as mulheres constituem a população estatisticamente mais empobrecida do globo, mas que as características da pobreza são intensificadas quando atreladas a elas e mais comuns nos lares por elas chefiados (COSTA; MEDEIROS, 2008). Por outras palavras, as condições de desigualdade de gênero fazem com que as mulheres vivenciem a pobreza com mais veemência do que os homens. 
Ao final da década de 1970, pesquisadoras europeias se debruçaram sobre esse processo, buscando suas aproximações com o a participação feminina no mercado de trabalho e com as políticas de bem-estar. ${ }^{5}$ Notou-se que há uma correlação entre o aumento do número de lares chefiados por mulheres e a deterioração de suas condições de vida, o que se deve, entre outros fatores, à dificuldade das mulheres para encontrar empregos de razoável remuneração, que é agravada por sua condição feminina. Além de preteridas pelos empregadores, que preferem reservar suas vagas aos homens, os vencimentos oferecidos a elas são inferiores aos destinados aos empregados do sexo masculino, mesmo quando ocupam as mesmas funções. As próprias políticas de assistência social reproduzem e institucionalizam as desigualdades de gênero e, muitas vezes, mantêm as mulheres em situação de pobreza (AGUILAR, 2011, p. 127).

A aparente emancipação da mulher e sua relativa independência do casamento acompanharam a sua inserção no mundo do trabalho remunerado, fazendo crescer o número de mulheres economicamente ativas, ainda que submetidas a trabalhos pouco qualificados. O provimento doméstico e conjugal das mulheres foi somado ao trabalho assalariado, permitindo que elas dispusessem de renda própria. Porém, o valor material, social e simbólico do seu próprio dinheiro não alterou as relações de poder no casamento e na família, embora tenha sido capaz de lhes garantir a possibilidade de uma vida privada não compartilhada com homens, já que, apenas com a sua própria renda, muitas mulheres puderam afrouxar seus vínculos familiares e conjugais (BECK, 2011, p. 117-118).

Por conseguinte, grávidas e abandonadas pelos companheiros, muitas mulheres passaram a liderar seus lares e a assumir o sustento de suas famílias, sendo responsáveis pelo cuidado com os filhos, pelas tarefas domésticas e pelo trabalho externo, a fim de bancar as despesas do lar. Sozinhas, precisam manter a si e a seus filhos, sendo obrigadas a encarar duplas ou triplas jornadas de trabalho. Isso não quer dizer que as

\footnotetext{
${ }^{5}$ A situação da mulher em geral e a situação da mulher chefe de família em particular foram analisadas por diversos estudos que assinalaram o impacto não fortuito do gênero na constituição da situação de pobreza, observando uma tendência de representação desproporcional das mulheres entre os pobres que é frequentemente invisibilizada. O processo de feminização da pobreza, por conseguinte, denota que os estratos sociais economicamente mais débeis estão se tornando cada vez mais femininos, dado que há, por sua vez, cada vez mais mulheres empobrecendo. Logo, a referência à pobreza diz respeito ao crescente ingresso de mulheres dentro desse estrato social, o que caracteriza a noção de feminização como uma tendência ou processo, no qual as assimetrias de gênero ocupam lugar importante. No entanto, outras dimensões da pobreza também devem ser associadas a essa noção, que deve contemplar discriminações legais, políticas e culturais que associam as mulheres à ausência de capacidade para o trabalho externo, relegando-as a um destino de domesticidade (AGUILAR, 2011, p. 129).
} 
famílias chefiadas por homens ou que integrem adultos do sexo masculino não possam enfrentar condições de pobreza iguais ou piores do que as referidas, mas o processo de feminização da pobreza aqui trabalhado demonstra que as mulheres sofrem um agravamento de sua penúria pelo simples fato de serem mulheres (NOVELLINO, 2004, p. 2; PEARCE, 1978, p. 28).

Mesmo com a expansão educacional que aumentou, de modo geral, os índices de escolaridade das mulheres, a sua relação com o trabalho doméstico não sofreu grandes alterações e ele ainda é visto como um destino que acompanha o sexo feminino com o casamento e, principalmente, com o nascimento dos filhos. As melhorias no acesso à educação e o consequente aumento do número de mulheres qualificadas consumaram um abandono parcial dos vínculos culturais de classe e da predestinação decorrente da origem social, mas tiveram pouca influência na diminuição das desigualdades de gênero (BECK, 2011, p. 119-120).

Para as mulheres, o caminho de ascensão profissional parece bloqueado pelo desemprego massivo e pela necessidade de dedicação ao lar, ao mesmo tempo que o caminho de volta à dependência do provimento conjugal e familiar também não é uma solução (BECK, 2011, p. 120).

A igualdade entre homens e mulheres na formação escolar escancarou os desníveis de suas posições na família e no trabalho. A evidência da injustiça, contudo, não impediu que as desigualdades se reproduzissem rotineiramente.

Os programas de combate à pobreza têm reproduzido padrões de discriminação ao encará-la como um problema social isolado e afastado das estruturas que sustentam as opressões sociais, desvinculando-o do capitalismo, do racismo e da dominação masculina. Os contextos macrossociais e econômicos que levam as mulheres chefes de família à situação de penúria, não podem ser desconsiderados, porque esta intersecciona, necessariamente, desigualdades de raça e gênero (AGUILAR, 2011, p. 130). O que há é uma feminização das causas da pobreza, considerando que as hierarquias de gênero atuam na produção e reprodução das situações de pobreza ao conceder às mulheres a responsabilidade integral pela manutenção de suas condições de vida e de seus descendentes (COSTA; MEDEIROS, 2008).

Ademais, percebe-se que o mercado de trabalho, atravessado pela desigualdade, reflete a colonialidade que caracteriza o país, expressando-se em termos racializados. Se, entre as mulheres brancas, cerca de $44 \%$ atuam em empregos 
informais, mais da metade das mulheres negras estão inseridas na informalidade, sem a possibilidade de desfrutar dos benefícios trazidos por um trabalho formal (MATOS; BORELLI, 2012). O cotidiano da segregação racial relega um enorme contingente de mulheres a um ciclo de vulnerabilidade social, do qual dificilmente conseguem sair.

Entre as mulheres brancas, a condição da mulher atuante como chefe de família é um fato recente, advindo com a intensificação da participação feminina no mercado de trabalho, porém, para as mulheres negras, essa já é uma realidade há bastante tempo, visto que, desde o período pós-abolição, grande parte das mulheres negras assumiram a posição de mantenedoras da família. Premidas pela responsabilidade com o sustento do lar, foram obrigadas a ingressar no mercado de trabalho em função das dificuldades incontestes enfrentadas pelos homens negros para trabalhar e também em razão da sobremortalidade destes. Outras, por sua vez, sem compartilhar a sua casa com companheiros homens, não tinham com quem dividir as despesas do lar nem a responsabilidade pela educação dos filhos, sendo levadas a uma situação de estagnação e pobreza (NEPOMUCENO, 2012, p. 396). Elas correspondem, pois, à maioria das famílias compostas por mães solteiras e seus descendentes.

A dupla jornada enfrentada tanto por mulheres brancas como negras, que passam a ser responsáveis, concomitantemente, por tarefas produtivas e reprodutivas, é, entretanto, agravada no caso das mulheres negras: os padrões socioeconômicos dos lares são piores nas famílias chefiadas por elas, independentemente do seu grau de escolaridade ou posição no mercado de trabalho. Além disso, elas enfrentam maiores dificuldades para oferecer cuidados básicos aos filhos, estando em posição desvantajosa em termos de moradia e renda familiar (NEPOMUCENO, 2012, p. 396).

Para as mulheres negras, mesmo a escolarização não é garantia de equivalência salarial e acesso a profissões valorizadas, porquanto a discriminação racial é determinante para a sua precária situação de vida. Em certa medida, os baixos níveis de escolaridade as aprisionaram em empregos de baixa remuneração, mas não explicam por completo a sua posição de maior subalternidade no mercado de trabalho.

Segundo os indicadores, as mulheres negras ocupam, maciçamente, postos de menor remuneração e maior vulnerabilidade, estando concentradas naquelas profissões tradicionalmente consideradas como femininas, tais qual a costura e o emprego doméstico. Ademais, estão sub-representadas nos cargos de direção e gerência. São elas que adentram mais precocemente no mercado de trabalho e que mais demoram para se 
aposentar, estando submetidas aos maiores índices de desemprego e menor cobertura previdenciária.

É evidente que, além da discriminação de gênero, que reserva às mulheres brancas e negras os piores empregos, estas sofrem, ainda, a discriminação racial, que Ihes coloca na berlinda da empregabilidade. Inseridas em um ciclo de vulnerabilidade, as mulheres negras recebem os piores salários e têm as jornadas de trabalho mais extensas, condição esta que, ao atingir suas filhas, é reproduzida pelas gerações futuras. Consequentemente, as mulheres negras, mais do que as brancas e mais do que os homens negros, representam um dos maiores contingentes de indigência e carestia do Brasil.

Se as mulheres e, em especial, as mulheres negras, ocupam uma posição de maior vulnerabilidade social, além de terem menor acesso aos bens da natureza, também são elas mais vitimadas pela distribuição desigual dos riscos do desenvolvimento. No Brasil, observa-se, por exemplo, que as mulheres constituem cerca de $70 \%$ do total de catadores de material reciclável, conforme dados do Movimento Nacional dos Catadores, trabalhando com o manuseio de materiais potencialmente perigosos para a sua saúde.

Estima-se que a maior parte dos deslocados ambientais são mulheres, forçadas a migrarem em razão de catástrofes ambientais ou de construções de grandes empreendimentos. Cita-se, a título de exemplo, o caso da construção da usina de Belo Monte, que obrigou comunidades ribeirinhas do Rio Xingu a deixarem seus lares e afetou desproporcionalmente as mulheres (PERTILLE, 2019).

Num prisma mais amplo, é de se notar que os corpos femininos são constantemente vítimas da vigilância e intromissão estatal. Nesse contexto, discursos e políticas higienistas de controle populacional visam majoritariamente as mulheres pobres e negras, apresentando-se como mais uma consequência nefasta do desenvolvimento.

No que diz respeito às catástrofes ambientais, emblemático foi o caso do ciclone que atingiu Bangladesh no ano de 1991, que, conforme Ferreira (2017, p. 19), teve mulheres e crianças como $90 \%$ de suas vítimas. Ressalta-se que os cuidados com o lar e com os filhos, a gravidez e a amamentação são alguns dos fatores que restringem a mobilidade feminina, dificultando a sua sobrevivência em situações de desastre. 
Segundo dados da IUCN, mulheres e crianças têm 14 vezes mais chances de morrer que homens durante um desastre. Em muitos países, mulheres têm posições de subordinação, mobilidade restrita, pouca oportunidade para estudos, menos poder de decisão e empregos mal remunerados, tudo o que amplia a vulnerabilidade (UNISDR, 2012, p. 22).

A nível mundial, dados da Plataforma Internacional de Redução de Desastres demonstram que, apenas entre 2005 e 2015, mais de 700 mil pessoas morreram em consequência de desastres ambientais, "mais de 1,4 milhão de pessoas ficaram feridas e cerca de 23 milhões ficaram desabrigadas". O documento afirma que as mulheres, as crianças e pessoas em condições de vulnerabilidade foram especialmente afetadas (UNIRSD, 2015).

\section{Considerações Finais}

Os indicadores sociais do processo de feminização da pobreza evidenciam, portanto, que os riscos e impactos ambientais provenientes da crise civilizacional que se expande em níveis globais afetam as mulheres subalternizadas de maneira muito mais gravosa do que a outros grupos sociais, inserindo-as numa posição de vulnerabilidade alarmante que deve ser levada em conta no momento da propositura de políticas sociais de cunho ecológico.

Os binarismos e desigualdades que hoje permeiam a sociedade são intrínsecos ao modelo civilizacional implementado desde o colonialismo, consubstanciando-se através das dominações de gênero, raça e classe que ainda hoje estruturam e organizam a sociedade em nível mundial. As bases dessas desigualdades precisam ser combatidas por meio de uma ação política que vise combater as situações de injustiça ambiental. Uma teoria da justiça baseada no individualismo liberal não atende a esses propósitos, sendo necessária a proposição de um projeto coletivo à frente de um movimento social por mudanças. Nesse sentido, acredita-se que o movimento de justiça ecológica é capaz de promover mudanças de cunho estrutural, pois tem como premissa a participação direta dos grupos oprimidos no processo democrático.

Não é à toa que a promoção da equidade de gênero aparece como um princípio norteador da justiça ecológica no documento intitulado "Declaração Mundial para o Estado de Direito Ambiental", resultado do 10 Congresso Mundial de Direito Ambiental 
da União Internacional para Conservação da Natureza, realizado em 2016, na cidade do Rio de Janeiro (LEITE et al, 2017, p. 172, 192). O fim da dominação de gênero, portanto, exige que as políticas públicas, decisões e práticas ambientais reconheçam que os riscos e impactos socioambientais atingem as mulheres de maneira desproporcional, sendo necessária e urgente a tomada de providências que visem a modificar esse cenário de desigualdade, o que precisa ser feito a partir de políticas que visem combater o processo de feminização da pobreza mencionado. Ademais, a importância do trabalho reprodutivo, ainda realizado em grande medida pelas mulheres, também deve ser posta em pauta no sentido de se reconhecer que a participação feminina é essencial para a sustentabilidade e para a proteção da natureza.

Sabe-se que os movimentos feministas e de mulheres apontam que o modelo econômico e cultural do Ocidente exige, para sua própria manutenção, a inferiorização feminina, de modo que a justiça ecológica precisa englobar à luta ambientalista contra a dominação da natureza a mobilização contra a subalternização das mulheres. Para tanto, a participação das minorias e dos estratos sociais desfavorecidos na tomada de decisões é prioritária em termos de política social ecológica. Conforme Spivak (2010), não basta representar os grupos sociais subalternizados, mas é preciso conceder-lhes a prerrogativa de falar por si.

A justiça ecológica deve dialogar com os feminismos, exigindo que políticas públicas e decisões direcionem a sua atenção, entre outros temas, para a erradicação das desigualdades sociais entre homens e mulheres que ainda se fazem tão presentes na sociedade hodierna. Logo, a implantação de um projeto eficaz de justiça ecológica exige que as políticas sociais do Estado se voltem, também, para a construção de uma sociedade igualitária em termos de gênero.

Referências Bibliográficas

ACSELRAD, Henri; MELLO, Cecília Campello do A.; BEZERRA, Gustavo das Neves. O que é justiça ambiental? Rio de Janeiro: Garamond, 2009.

AGUILAR, Paula Lucía. La feminización de la pobreza: conceptualizaciones actuales y potencialidades analíticas. Revista Katálysis, Florianópolis, v. 14, n. 1, p. 126-133, jan./jun. 2011. 
BAGGIO, Roberta Camineiro. Justiça ambiental entre redistribuição e reconhecimento: a necessária democratização da proteção da natureza. 2008. Tese (Doutorado em Direito), Universidade Federal de Santa Catarina, Florianópolis, 2008.

BALLESTRIN, Luciana. América Latina e o giro decolonial. Revista Brasileira de Ciência Política, Brasília, n. 11, p. 89-117, maio/ago. 2013.

BECK, Ulrich. Sociedade de risco: rumo a uma outra modernidade. 2. ed. São Paulo: Editora 34, 2011.

BOYD, David R. The rights of nature: a legal revolution that could save the world. Toronto: ECW Press, 2017.

CAPDEVILLE, Fernanda de Salles Cavedon. A mobilidade humana na agenda global do clima: uma questão de justiça climática. In: LEITE, José Rubens Morato; DINNEBIER, Flávia França (Orgs.). Estado de direito ecológico: conceito, conteúdo e novas dimensões para a proteção da natureza. São Paulo: Instituto o Direito por um Planeta Verde, 2017, p. 482-509.

COSTA, Joana; MEDEIROS, Marcelo. What do we mean by "feminization of poverty"? International Poverty Centre, Brasília, n. 58, jul. 2008.

FERREIRA, Maria Augusta Soares de Oliveira. A campanha da fraternidade ecumênica de 2016 na perspectiva do ecofeminismo e da justiça socioambiental. In: CIRNE, Lúcio Flávio R.; CLAUDIO, Maria do Rozário; MONTEIRO, Valdênia Brito (Orgs.). Mulher, vulnerabilidade e justiça socioambiental. Recife: Instituto Humanitas, 2017.

LEFF, Enrique. Racionalidade ambiental: a reapropriação social da natureza. Rio de Janeiro: Editora Civilização Brasileira, 2006.

LEITE, José Rubens Morato; SILVEIRA, Paula Galbiatti; Bettega, Belisa. Princípios estruturantes do estado de direito para a natureza. In: LEITE, José Rubens Morato; DINNEBIER, Flávia França (Orgs.). Estado de direito ecológico: conceito, conteúdo e novas dimensões para a proteção da natureza. São Paulo: Instituto o Direito por um Planeta Verde, 2017, p. 166-201.

MATOS, Maria Izilda Santos de; BORELLI, Andrea. Espaço feminino no mercado produtivo. In: PINSKY, Carla Bassanezi; PEDRO, Joana Maria (Org.). Nova história das mulheres no Brasil. São Paulo: Contexto, 2012, p. 126-147.

MATOS, Maria Izilda Santos de. Terceiro setor e gênero: trajetórias e perspectivas. São Paulo: Cultura Acadêmica, 2005.

MELO, Melissa Ely. Pagamento por serviços ambientais (PSA): entre a proteção e a mercantilização dos serviços ecossistêmicos no contexto da crise ambiental. Tese (Doutorado em Direito) - Programa de Pós-Graduação em Direito, Universidade Federal de Santa Catarina, Florianópolis, 2016.

MENDES, Soraia da Rosa. Criminologia feminista: novos paradigmas. São Paulo: Saraiva, 2014. 
NEPOMUCENO, Bebel. Protagonismo ignorado. In: PINSKY, Carla Bassanezi; PEDRO, Joana Maria (Org.). Nova história das mulheres no Brasil. São Paulo: Contexto, 2012, p. 382-409.

NOVELLINO, Maria Salet Ferreira. Os estudos sobre feminização da pobreza e políticas públicas para mulheres. In: Anais do XXVIII Encontro Anual da ANPOCS. Caxambu: ANPOCS, 2004.

QUIJANO, Anibal. Colonialidade do poder, eurocentrismo e América Latina. In: LANDER, Edgardo (Org.). A colonialidade do saber: eurocentrismo e ciências sociais. Perspectivas latino-americanas. Buenos Aires: CLACSO, 2005, p. 227-278.

PEARCE, Diane. The feminization of poverty: women, work and welfare. Urban \& Social Change Review, Boston, v. 11, n. 1/2, p.28-36. 2008.

PERTILLE, Thais Silveira. Direitos Humanos das deslocadas ambientais e os impactos da Usina de Belo Monte: a influência internacional nas capacidades humanas centrais. Dissertação (Mestrado em Direito) - Programa de Pós-Graduação em Direito, Universidade Federal de Santa Catarina, Florianópolis, 2019.

RAMMÊ, Rogério Santos. Da justiça ambiental aos direitos e deveres ecológicos: conjunturas político-filosóficas para uma nova ordem jurídico-ecológica. Caxias do Sul: Educs, 2012.

RESTREPO, Eduardo; ROJAS, Axel. Inflexión decolonial: fuentes, conceptos y cuestionamientos. Popatán: Universidad del Cauca; Instituto Pensar, Universidad Javeriana, 2010.

SANTOS, Milton. Por uma outra globalização: do pensamento único à consciência universal. 6. ed. Rio de Janeiro: Record, 2001.

SCHLOSBERG, David. Defining environmental justice: theories, movements, and nature. United Kingdom: Oxford University Press, 2007.

SCOTT, Joan Wallach. Género e historia. Ciudad de México: Universidad Autónoma de la Cuidad de México, 2008.

SEGATO, Rita Laura. La crítica de la colonialidad en ocho ensayos: y una antropología por demanda. Buenos Aires: Prometeo Libros, 2013.

SILVA, Solange Teles da. Estado de direito ambiental e ecofeminismo: desafios para a construção de uma sociedade igualitária. In: LEITE, José Rubens Morato; DINNEBIER, Flávia França (Orgs.). Estado de direito ecológico: conceito, conteúdo e novas dimensões para a proteção da natureza. São Paulo: Instituto o Direito por um Planeta Verde, 2017, p. 566-584.

SPIVAK, Gayatri Chakravorty. Pode o subalterno falar? Tradução de Sandra Regina Goulart Almeida, Marcos Pereira Feitosa e André Pereira Feitosa. Belo Horizonte: UFMG, 2010. 
SUGAI, Maria Inês. Segregação silenciosa: investimentos públicos e dinâmica socioespacial na área conurbada de Florianópolis (1970-2000). Florianópolis: Editora da UFSC, 2015.

Sobre a autora

Camila Damasceno de Andrade

Doutoranda do Programa de Pós-Graduação em Direito da Universidade Federal de Santa Catarina (PPGD/UFSC). Mestra em Direito pelo PPGD/UFSC. Graduada em Direito pela UFSC. Professora do curso de Direito na Universidade do Sul de Santa Catarina (UNISUL). E-mail: camila_damasceno17@hotmail.com. ORCID: https://orcid.org/0000-0002-5907-3541.

A autora é a única responsável pela redação do artigo. 